\title{
Formation of reactive oxygen species and (iron)silicate (nano)particles in the mixing zone above hydrothermal vent orifices
}

\author{
G. W. LUTHER ${ }^{1 *}$, T.J. SHAW ${ }^{2}$, E.R. ESTES ${ }^{1 *}$, D. BERTI ${ }^{3}$,
} M.F. HOCHELLA ${ }^{3}$, M. YUCEL ${ }^{4}$, A.J. FINDLAY ${ }^{1}$, J. L.

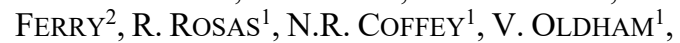
D.M.C. DIAS ${ }^{2}$

${ }^{11}$ University of Delaware, 700 Pilottown Road, Lewes, DE, USA, 19968, (*correspondence; luther@udel.edu)

${ }^{2}$ Department of Chemistry and Biochemistry, University of South Carolina, 631 Sumter Street, Columbia, SC 29208, USA, (shaw@mailbox.sc.edu)

${ }^{3}$ NanoEarth Center, 1991 Kraft Drive, Blacksburg, VA, USA, 24061, (hochella@vt.edu)

${ }^{4}$ Middle East Technical University, Erdemli Campus, Mersin, Turkey, (myucel@ims.metu.edu.tr)

The dynamic mixing zone within the first two meters of hydrothermal vent orifices leads to myriad reactions. Here we demonstrate the formation of reactive oxygen species (ROS) as dissolved $\mathrm{Fe}(\mathrm{II})$ and $\mathrm{FeS}$ nanoparticles from vent rich waters react with $\mathrm{O}_{2}$ from cold ambient waters, and the formation of silicate phases containing $\mathrm{Mg}$ and/or Fe at vents from $9^{0} 50^{\prime}$ North East Pacific Rise. Plume waters were drawn into syringes preloaded with horseradish peroxidase enzyme and Amplex Red to immediately convert ambient hydrogen peroxide, $\mathrm{H}_{2} \mathrm{O}_{2}$, to the stable fluorophore, resorufin. Hydrogen peroxide at levels as high as 6.2 micromolar were found in plume and seep waters, and correlated with initial $\mathrm{O}_{2}$ concentration anticipated during mixing. Data indicate that an $\mathrm{Fe}-\mathrm{O}_{2}-\mathrm{Mn}-\mathrm{H}_{2} \mathrm{~S}$ catalytic cycle developed with formation of $\mathrm{S}_{8}$. Formation of $\mathrm{H}_{2} \mathrm{O}_{2}$ in the presence of dissolved $\mathrm{Fe}(\mathrm{II})$ leads to hydroxyl radicals that can react with refractory materials including organic compounds. Similarly, Mg, which is depleted in vent waters, reacts with silica emanating from vents to from silicates. Selected area electron diffraction patterns of (nano)particles show that $\mathrm{Mg}$ - and Fe-bearing silicate phases form in the mixing zone. The mineral phases include kaolinite, Fe-rich micas, and talc/lizardite; their formation in the plume is an example of reverse weathering. These particles are ubiquitous in sampled fluids and are a previously undocumented source of Fe to the global ocean. 